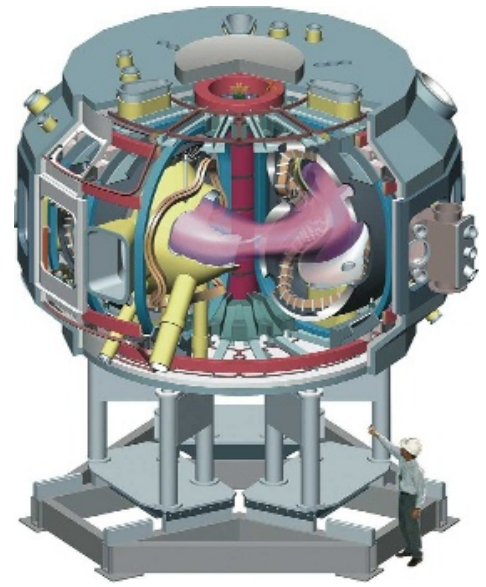

The National Compact Stellarator Experiment never made it out of the design phase.

\section{Plug pulled on stellarator fusion project}

The US Department of Energy has cancelled a major fusion experiment.

Based at Princeton Plasma Physics Laboratory in New Jersey, the US\$100-million National Compact Stellarator Experiment (NCSX) faced construction delays and cost overruns (see Nature 449, 264; 2007) estimated in terms of years and tens of millions of dollars.

On 22 May, Raymond Orbach, the department's undersecretary for science, announced that NCSX would be terminated to free up funds for other fusion experiments, including ITER, an international \$12-billion tokamak under construction in Cadarache, France.

\section{Funding boost for B-cell- based HIV vaccine research}

In an effort to speed up HIV vaccine research, the US National Institute of Allergy and Infectious Diseases (NIAID) last week awarded US\$15.6 million in grants for research on B-cell immunology.

The five-year awards will go to ten research teams. They come two months after NIAID director Anthony Fauci announced his institute's intention to "turn the knob" in the direction of basic research and discovery (see Nature 452, $503 ; 2008)$ after the highly public failure of a T-cell-based HIV vaccine candidate.

"This is the kind of thing we were talking about when we were talking about discovery," says Fauci, who says that planning for the awards began 14 months ago. $B$ cells make antibodies that neutralize invading viruses, but humans seem unable to mount a response during HIV infection.

\section{Japan to allow limited human embryonic cloning}

Last week, an expert committee in Japan's science ministry agreed to lift a 2001 ban on human cloning for research purposes. The amendment, expected to be effective later this year, maps out rigorous ethical regulations under which the research could proceed. Reproductive cloning would still be illegal.

A group in Japan has expressed intentions to clone embryos for research. But serious hurdles remain, including the low availability of human eggs for research due to strict prohibitions on compensation.

\section{Correction}

The 2002 biosolids study from the National Academy of Sciences (NAS) did not reference research into health impacts by Environmental Protection Agency (EPA) whistleblower David Lewis, as reported in our News story 'Raking through sludge exposes a stink' (Nature 453, 262-263; 2008). The citation was included in a prepublication draft that is still posted on the EPA's internet site, but the NAS panel voted to remove the reference before final publication. An NAS spokesman said the panel decided the information was not relevant as the panel was not charged with evaluating health impacts. 